\title{
Acid Resistance of the Enamel in Primary Second Molars from Children with Down Syndrome and Cerebral Palsy
}

\author{
David Keinan ${ }^{1}$, Anna Radko ${ }^{2}$, Patricia Smith ${ }^{1}$ and Uri Zilberman ${ }^{1, *}$ \\ ${ }^{I}$ Laboratory of Bioanthropology and Ancient DNA, Hadassah School of Dental Medicine, Hebrew University, POB \\ 12272, Jerusalem, 91120, Israel and ${ }^{2}$ The Unit for Nanoscopic Characterization, The Hebrew University of Jerusalem, \\ E. Safra Campus Givat Ram, Jerusalem, 91904, Israel
}

\begin{abstract}
Objectives: This study was carried out to evaluate the extent of differences in mineralization of inner and outer enamel of the lower primary second molars of children with Down syndrome (DS) and Cerebral Palsy (CP) as revealed by acid treatment of exfoliated teeth. The results were compared to those obtained from a control group of healthy children.

Methods: The sample included 4 mandibular second molars from each group. On each tooth, a thin section was cut, bisecting the mesial cusps. The analysis was carried out on the mesio-buccal cusps. Atomic force microscopy (AMF) was used to analyze the morphological structure of the dental enamel after $10 \mathrm{sec}$ of $0.1 \mathrm{~mol} \%$ citric acid treatment. The measurements were performed on 3 points in the enamel close to the outer surface and 3 points in the enamel close to the dentin. The differences between groups were analyzed using Mann Whitney tests.

Results: In controls and CP teeth the outer enamel was more resistant to etching than the inner enamel. In DS teeth both outer and inner enamel showed similar results for all parameters. Between group comparisons showed that roughness values were significantly higher $(\mathrm{P}<0.01)$ in DS teeth than in either controls or CP teeth. No significant differences were found between $\mathrm{CP}$ and control teeth.

Conclusions: The higher values obtained for DS enamel reflect increased solubility of the enamel to acid relative to controls and CP teeth together with irregularity of the organic matrix. The practical importance of the results is that DS primary molars needs reduced etching time when prepared for pit and fissure sealants or composite/compomer restorations.
\end{abstract}

Key Words: Down syndrome, cerebral palsy, enamel, acid treatment, AFM.

\section{INTRODUCTION}

It is well known that stress of sufficient severity to affect development leaves a permanent imprint on the teeth and its location reflects the timing and duration of such events [1].

Bio-mineralization of tooth enamel takes place in a highly structured organic matrix laid down by the ameloblasts and is divided into three stages classified as forming, maturing and mature [2-4], during which mineral content increases and the organic content decreases. Impaired ameloblast function will affect the quantity and integrity of the organic matrix and so affect the orientation and growth of the apatite crystals and subsequent degradation and removal of the organic matrix.

The primary second molars (DM2) are especially suitable for analysis of developmental disturbances. In those teeth, bio-mineralization of the mesio-buccal and mesio-lingual cusps begins at approximately 22 weeks in utero and in the disto-buccal and disto-lingual cusps at 26 weeks in utero and crown formation is completed 10 month after birth [5].

The influence of developmental insults on the biomineralization of mandibular primary second molars was

*Address correspondence to this author at the Laboratory of Bioanthropology and Ancient DNA, Hadassah School of Dental Medicine, Hebrew University, POB 12272, Jerusalem, 91120, Israel; Tel: +972 -2-6758577; Fax: +972-2-6757451; E-mail: uri-z@smile.net.il studied by Keinan et al. [6] by comparing prenatal enamel formed to post natal enamel development. Their research showed that on the early formed mesial cusps the thickness of prenatal enamel was significantly reduced in Down syndrome and cerebral palsy compared to normal teeth. Furthermore, the $\mathrm{Ca} / \mathrm{P}$ ratios were significantly higher in DS and $\mathrm{CP}$ teeth compared to normal controls, indicating reduced hydroxyapatite component in the enamel.

Primary teeth have higher $\mathrm{Ca} / \mathrm{P}$ ratio than permanent teeth as a result of calcium bonded to other elements than phosphate [4]. It is well known that different calcium crystals in the enamel have different resistance to acid treatment $[7,8]$. Other studies have shown correlation between $\mathrm{Ca} / \mathrm{P}$ ratio and microhardness $[9,10]$.

Micromechanical properties of teeth were studied on permanent molars using micro-hardness test performed with Vickers and Knoop indenters. In sound human enamel, the hardness values, mineral content and density have been reported to gradually decrease from the outer surface to the dentino enamel junction (DEJ) [11-14].

Correlation between calcium content and microhardness of decalcified enamel was reported [12]. In etched enamel the microhardness values were at a lower level compared to untreated enamel. The change in microhardness of enamel has been correlated with decrease in calcium concentration 
after slow decalcification and etching [7, 8]. The hardness experiment indicates that the structure after etching is not comparable to that of a caries like lesion as a result of slow demineralization. Difference in the nano-mechanical properties between the enamel prisms and their surrounding sheaths of extracted third molars were reported [15]. The nanohardness of the enamel of third molars revealed differences between the tail of the rods and inter-rod enamel to that of the head of the rods- the values (Young's moduli and hardness) for the head of the rods were higher. Those differences were attributed to changes in crystal orientation and the higher content of soft organic tissue [16].

On the basis of these results we propose that examination of the nanomechanical characteristics using atomic force microscopy (AFM) may reveal differences in the chemical composition and the enamel matrix of teeth from children with developmental disorders.

Down syndrome (DS) is caused by trisomy of the $21^{\text {st }}$ chromosome. In those patients the postnatal growth and development are progressively impaired [17-21]. Dental anomalies previously reported range from hypodontia [22] to microdontia of the second deciduous molar and permanent teeth, although earlier forming primary teeth are larger than those of normal controls [19, 20], altered crown morphology $[23,24]$, and reduced enamel thickness $[17,18]$.

Cerebral palsy (CP) is a non-progressive defect of the central nervous system [25]. The vast majority of cases $(85 \%)$ are congenital, but it is still unclear whether they result from developmental insults in utero, or during parturition [26-29]. A high frequency of enamel defects and a thickened neonatal line has been reported in this condition $[26,30]$.

In order to examine the extent of differences in quality of the enamel matrix, nano-roughness of the mesiobuccal cusps of primary lower second molars was evaluated by AFM analysis of the resistance of enamel to acid etching. This analysis was carried out by comparing the roughness measured at different areas of the enamel after polishing and acid treatment.

\section{MATERIALS AND METHODS}

This study was carried out on ground sections derived from exfoliated primary lower second molars. The teeth belonged to three groups: children with no adverse medical history (controls), children with DS, and children with CP. The sample comprised sections from 12 teeth, 4 from each group. The teeth were immersed in acrylate according to the protocol of Caropreso et al. [31], and a 200 micrometer thick section was obtained from each tooth using a standard procedure in which the section was made through the tips of the mesial cusps (mesiobuccal and mesiolingual) parallel to the long axis of the tooth, with a Beuhler isomet diamond wafering-blade saw. The sections were then polished using a 600 grit polishing paper to a thickness of 100-150 micrometers. The sections were immersed in citric acid $(0.1 \mathrm{~mol} \%)$ for 10 seconds, rinsed with water and dried at room temperature. The sections were then examined using an Atomic Force Microscope (AFM), (D3100, Nanoscope IVa, Veeco, Santa Barbara, CA, USA) in order to determinate the surface roughness of outer and inner areas of enamel. The topog- raphic images $(20 \mu m \mathrm{X} 20 \mu \mathrm{m})$ were obtained in air in tapping mode using etched silicon probes (TESP, Veeco). On the mesiobuccal cusp tip of each section, three independent measurements were taken at standard locations on the inner and outer enamel (Fig. 1). Image roughness $\left(\mathrm{R}_{\mathrm{q}}\right), \mathrm{Z}$ range and surface area difference $(\% \mathrm{SA})$, were obtained from each location.

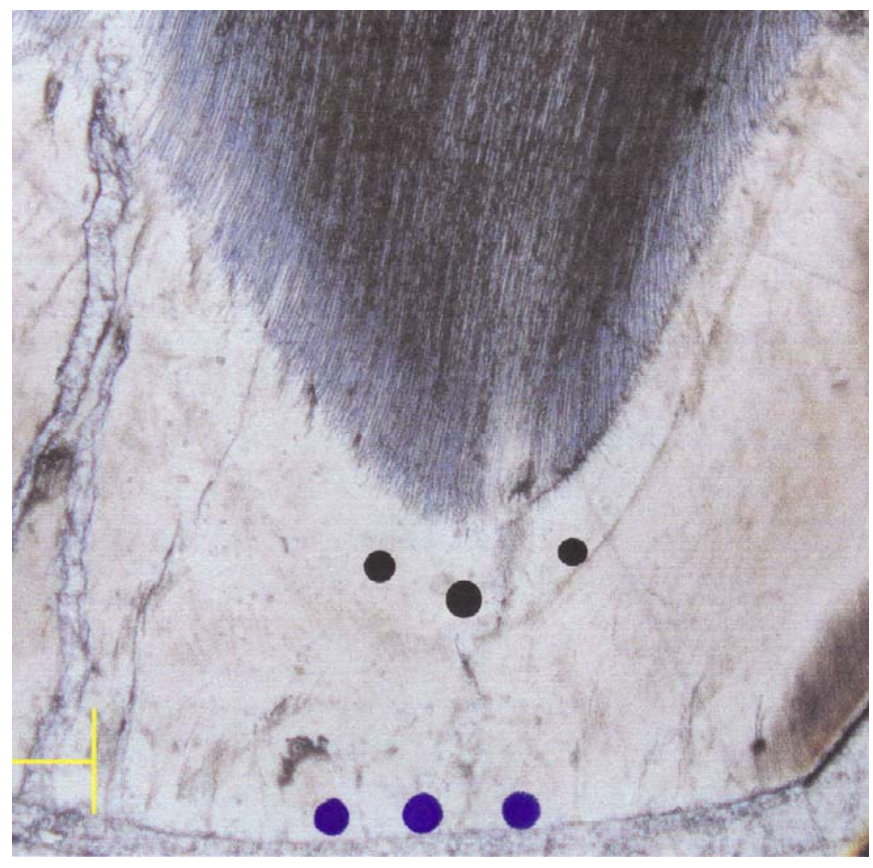

Fig. (1). Location of the measurements points on the inner (prenatal) and outer (postnatal) aspects of enamel.

1. Image roughness $(\mathbf{R q})$ - Root mean square average of height deviations taken from the mean image data plans.

2. Image $\mathbf{Z}$ range - Maximum vertical distance between the highest and lowest data points in the image prior to the plane fit.

3. Image surface area difference $(\% \mathbf{S A})$ - Difference between the image's three-dimensional surface area and two-dimensional projected surface areas.

The differences between groups were analyzed statistically using Mann Whitney U tests.

\section{RESULTS}

The AFM images were obtained from the inner and from the outer aspect of the enamel of teeth from CP, DS and control children. The entire sample was polished to the same level; therefore differences in the roughness data indicate differences in the resistance of the enamel to acid treatment. Fig. (2) shows the topographic images of inner aspect of enamel from each group after acid treatment. The difference in architecture of the enamel in the three groups is clearly visible. Fig. (2A) shows the characteristic structure of enamel for normal teeth. The well-defined shape long rods with pronounced borders appear on the topographic image. The long extended rods are also observed on CP sample, Fig. (2B). In this case the borders of the rods are not so clearly defined. These structures cannot be observed on DS sample, 
in Fig. (2C). In comparison with two previous samples, the surface of DS samples shows marked irregularity.

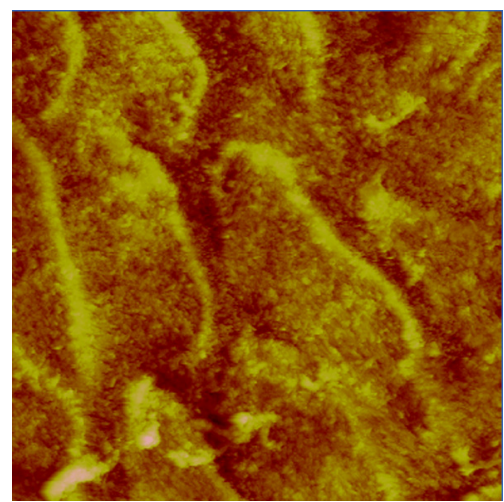

A: Control

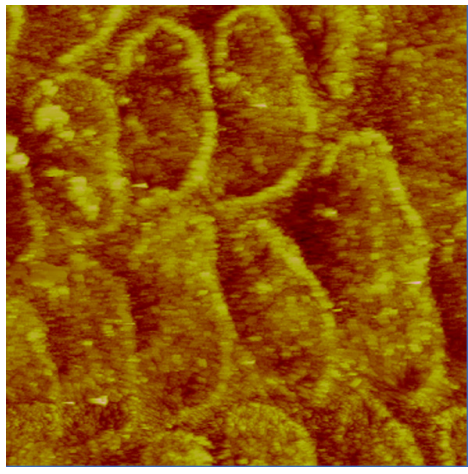

B: $\mathrm{CP}$

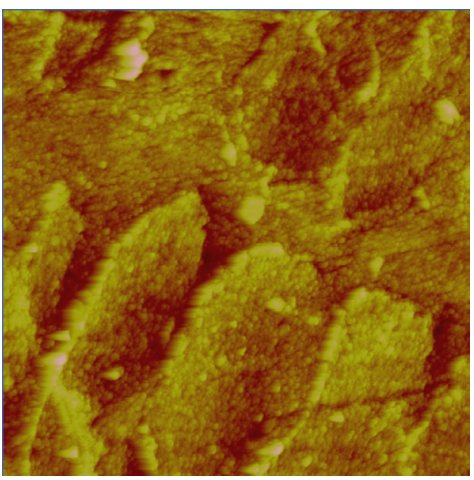

C: DS

Fig. (2). Prism pattern of the inner aspect of normal, CP and DS primary second molars after etching.

Table 1 shows the mean $\mathrm{R}_{\mathrm{q}}, \mathrm{Z}$ range and $\% \mathrm{SA}$ in the inner and outer enamel aspect of each set of measurements taken on each section for normal, CP and DS teeth.

In controls and DS, the average values for $\mathrm{Rq}$ and $\mathrm{Z}$ range were higher in the inner enamel, while \%SA was higher in the outer enamel. In CP teeth, the average values for all parameters $(\mathrm{Rq}, \mathrm{Z}$ range and SA\%), were higher in the inner enamel compared to those at the outer aspect. For all measurements taken, increased range was observed in the outer enamel.

Both inner and outer enamel aspects of DS teeth showed higher values for all parameters analyzed ( $\mathrm{Rq}, \mathrm{Z}$ range and $\% \mathrm{SA}$ ) than either the controls or $\mathrm{CP}$ teeth, and the differences were significant statistically $(\mathrm{P}<0.01)$. The differences between $\mathrm{CP}$ and control teeth were not significant. The roughness pattern in DS teeth was twice to five times greater than that of controls or CP teeth.

Table 2 summarizes the ratio between outer and inner enamel aspects of each section for each set of measurements taken on normal, CP and DS teeth. For all groups the average ratio between inner to outer enamel was greater than 1 , implicating greater roughness on the inner aspect after the acid treatment. In controls and CP teeth the inner enamel roughness was $35-56 \%$ greater than measured in the outer enamel. In DS teeth the differences between inner and outer enamel aspects were minimal (5-16\%), showing similar roughness on both inner and outer enamel after acid treatment. The ratio of inner to outer enamel roughness in DS was significantly lower than that in controls or $\mathrm{CP}(\mathrm{P}<0.01)$.

\section{DISCUSSION}

The roughness parameters measured in this research reveal the behavior of the primary second molar enamel to acid attack.

In the control group the ratios between inner and outer enamel values were positive for all parameters, implying that the resistance of the inner enamel to acid attack is less than that of the outer enamel. Several studies demonstrated the same pattern in permanent teeth [11-14]. The reduced resistance to acid treatment may be related to differences in the chemical composition, as the decreased resistance to acid attack follows increase in the enamel carbonate concentration [7, 8]. Robinson et al. [32] found that fluoride concentrations decreased from enamel surface to EDJ, while carbonate and magnesium concentrations increased (from 4-6\% to $2 \%$, and from $0.2 \%$ to $0.5 \%$ respectively).

Controls and CP teeth showed similar values, without any significant differences, and the resistance of both groups to acid was similar. The striking finding was that the results for DS molars were 3-5 times higher than controls or CP. The results for roughness showed that the microstructure of the hydroxyapatite in DS is different than that of CP and controls and that the resistance of DS primary teeth to acid attack was very low. This presumably was caused by the high concentration of calcium compounds, other than hydroxyapatite, as reported by Keinan et al. [6] in DS primary molars. The differences found in nano-roughness between the three groups can be observed in Fig. (2). This low resistance to acid attack in DS primary molars can be compared to hypomineralized regions in permanent teeth as measured by Mahoney et al. [33]. Al-Jawad et al. [34] have shown that changes in lattice parameters are primarily associated with changes in the chemical composition of the enamel in different regions of the tooth. Cuy et al. [14] demonstrated that the crystallographic and mechanical properties of enamel are closely linked.

In a previous study, Keinan et al. [2006], showed impaired development and mineralization of lower primary second molars in DS and CP groups (Table 3). Their results showed that significantly less enamel was laid down prenatally in DS and CP teeth compared to the control group. Enamel biomineralization has been described as a "spontaneous assembly and hierarchial organization of birefringent microribbons" primarily composed of amelogenin that pro- 
Table 1. Roughness Parameters (Mean for 3 Points and Range) Measured on the Inner and Outer Enamel of the Normal, CP and DS Primary Second Molars. Each Group Comprised of 4 Teeth

\begin{tabular}{|c|c|c|c|c|c|c|}
\hline & \multicolumn{3}{|c|}{ Inner Enamel } & \multicolumn{3}{|c|}{ Outer Enamel } \\
\hline & $\mathbf{R q}$ & Z Range & $\% \mathrm{SA}$ & $\mathbf{R q}$ & Z Range & $\% \mathrm{SA}$ \\
\hline $\mathrm{CP}$ & $\begin{array}{c}\text { 32.00 } \\
(27.4-46.2)\end{array}$ & $\begin{array}{c}\mathbf{2 3 9 . 3 6} \\
(202-299)\end{array}$ & $\begin{array}{c}\mathbf{8 . 9 8} \\
(5.1-14.3)\end{array}$ & $\begin{array}{c}\mathbf{2 7 . 9 8} \\
(11.2-54.1)\end{array}$ & $\begin{array}{c}\mathbf{2 0 7 . 0 8} \\
(108-346)\end{array}$ & $\begin{array}{c}\mathbf{7 . 2 9} \\
(3.2-15.4)\end{array}$ \\
\hline DS & $\begin{array}{c}\text { 196.44* } \\
(140-235)\end{array}$ & $\begin{array}{c}\mathbf{1 1 9 0 . 4 4 *} \\
(822-1467)\end{array}$ & $\begin{array}{c}\mathbf{1 8 . 8 1}^{*} \\
(6.8-30.7)\end{array}$ & $\begin{array}{c}\text { 189.2* } \\
(143-271)\end{array}$ & $\begin{array}{c}\mathbf{1 2 4 2 . 1}^{*} \\
(1020-1882)\end{array}$ & $\begin{array}{c}\mathbf{2 6 . 1 3}^{*} \\
(7.26-70.3)\end{array}$ \\
\hline
\end{tabular}

Note: CP-cerebral palsy, DS- Down syndrome.

$*=\mathrm{P}$ value $<0.01$ compared to controls or $\mathrm{CP}$.

$\mathrm{Rq}$ - Image roughness - Root mean square average of height deviations taken from the mean image data plans.

$\mathrm{Z}$ range - Maximum vertical distance between the highest and lowest data points in the image prior to the plane fit.

$\%$ SA - Image surface area difference - Difference between the image's three-dimensional surface area and two dimensional projected surface areas.

Table 2. Ratios of the Different Roughness Parameters (Mean and Range) Calculated in the Outer and Inner Enamel Aspects for Normal, CP and DS Teeth

\begin{tabular}{|c|c|c|c|}
\hline & Rq Inner/Outer & Z Inner /Outer & \%SA Inner /Outer \\
\hline \hline $\begin{array}{c}\text { Normal } \\
(\mathrm{n}=4)\end{array}$ & $\begin{array}{c}\mathbf{1 . 5 0} \\
(0.89-2.95)\end{array}$ & $\begin{array}{c}\mathbf{1 . 3 7} \\
(0.89-2.42)\end{array}$ \\
\hline $\begin{array}{c}\mathrm{CP} \\
(\mathrm{n}=4)\end{array}$ & $\begin{array}{c}\mathbf{1 . 3 7} \\
(0.71-3.05)\end{array}$ & $\begin{array}{c}\mathbf{1 . 3 5} \\
(0.78-2.56)\end{array}$ & $\mathbf{1 . 5 6}$ \\
\hline $\mathrm{DS}$ & $\begin{array}{c}\mathbf{1 . 1 1 *} \\
(\mathrm{n}=4)\end{array}$ & $\begin{array}{c}\mathbf{1 . 1 6 *} *-37-3.05) \\
(0.72-3.69\end{array}$ & $\mathbf{1 . 0 5 *}$ \\
\hline
\end{tabular}

Note: CP-cerebral palsy, DS- Down syndrome.

$*=\mathrm{P}$ value $<0.01$ compared to controls or $\mathrm{CP}$.

$\mathrm{Rq}$ - Image roughness - Root mean square average of height deviations taken from the mean image data plans.

$\mathrm{Z}$ range - Maximum vertical distance between the highest and lowest data points in the image prior to the plane fit.

$\%$ SA - Image surface area difference - Difference between the image's three-dimensional surface area and two dimensional projected surface areas.

Table 3. Mineral Content (Mean and Range) of the Mesial Cusps of Normal, DS and CP Primary Second Molars

\begin{tabular}{|c|c|c|c|}
\hline & Calcium & Phosphate & Ca/P Ratio \\
\hline \hline Normal & $\mathbf{3 1 . 7 7}(25.65-36.85)$ & $\mathbf{1 5 . 1 4}(13.45-16.81)$ & $\mathbf{2 . 0 9}(1.74-2.24)$ \\
\hline CP & $\mathbf{3 6 . 2 0}(33.25-37.85)$ & $\mathbf{1 6 . 2 5}(15.30-17.07)$ & $\mathbf{2 . 2 3} *(2.09-2.31)$ \\
\hline DS & $\mathbf{3 3 . 2 1}(16.02-39.07)$ & $\mathbf{1 5 . 1 0}(13.06-17.21)$ & $\mathbf{2 . 1 9 *}(2.07-2.32)$ \\
\hline
\end{tabular}

Note: The data is from Keinan et al. 2006.

$*=\mathrm{P}$ value $<0.05$ compared to normal.

vides the three dimensional framework on which hydroxyapatite crystals assemble and aggregate [35]. The biomineralization of DS was poorer than that of controls (greater $\mathrm{Ca} / \mathrm{P}$ ratio) but seemed better than that of $\mathrm{CP}$. Based on the previous data, Keinan et al. [2006] the expectation was that DS teeth will show also roughness values between the controls and $\mathrm{CP}$ teeth, following the acid treatment. The results described in this paper showed that acid etching has significantly greater influence on the DS enamel. We found high irregularity in enamel surface morphology of DS samples following the acid attack, greater than those observed in controls and $\mathrm{CP}$ teeth. Those differences in nanostructure after etching may represent different prism pattern that influences acid sensitivity. Combining the data from the chemical analysis we may assume that DS primary molars showed the faster decalcification process, causing abnormal prism morphology and interprismal defects, with little or no relevance to the $\mathrm{Ca} / \mathrm{P}$ ratios.

\section{CONCLUSIONS}

The effect of acid on the enamel of primary second molars of Down syndrome and CP children was compared to normal population. Although the primary molars of Down 
syndrome showed a better $\mathrm{Ca} / \mathrm{P}$ ratio than that of $\mathrm{CP}$ teeth the results obtained in this study showed that in Down syndrome primary molars the enamel is softer probably due to calcium compounds other than hydroxyapatite. The practical importance of the results in dental practice is that the etching treatment in primary molars in DS should be reduced.

\section{REFERENCES}

[1] Ten Cate AR. Oral histology. development, structure, and function. $5^{\text {th }}$ ed. St. Louis: the C.V. Mosby Co 1998; 73-102.

[2] Deutsch D, Gedalia I. Chemically distinct stages in developing human fetal enamel. Arch Oral Biol 1980; 25: 635-9.

[3] Deutsch D, Pe'er E. Development of enamel in human fetal teeth. J Dent Res 1982; 61: 1543-51.

[4] Deutsch D, Shapira L. Changes in mineral distribution and concentration during enamel development in the deciduous human maxillary and mandibular teeth. Growth 1987; 51:334-41.

[5] Kraus BS, Jordan RE. The human dentition before birth. Lea and Febiger, Philadelphia 1965; pp. 136-8.

[6] Keinan D, Zilberman U, Smith P. Microstructure and chemical compostion of primary teeth in children with down syndrome and cerebral palsy. Arch Oral Biol 2006; 51: 836-43.

[7] Meurman JH, Hemmerlé J, Voegel JC, Rauhamaa-Mäkinen R, Luomanen M. Transformation of hydroxyapatite to fluorapatite by irradiation with high-energy CO2 laser. Caries Res 1997; 31: 397400.

[8] Tanaka K, Iijima Y. Acid resistance of human enamel in vitro after bicarbonate application during remineralization. J Dent 2001; 29: 421-6.

[9] Kodaka T, Debari K, Yamada M, Kuroiwa M. Correlation between microhardness and mineral content in sound human enamel. Caries Res 1992; 26: 139-41.

[10] Davidson CL, Hoekstra IS, Arends J. Microhardness of sound, decalcified and etched tooth enamel related to the calcium content. Carries Res 1974; 8: 135-44.

[11] Caldwell RC, Muntz ML, Gilmore RW, Pigman W. Microhardness studies of intact surface enamel. J Dent Res 1957; 36: 732-8.

[12] Davidson CL, Hoekstra IS, Arends J. Microhardness of sound, decalcified and etched tooth enamel related to the calcium content. Caries Res 1974; 8: 135-44.

[13] Robinson C, Weatherell JA, Hallsworth AS. Distribution of magnesium in mature human enamel. Caries Res 1981; 15: 70-7.

[14] Cuy JL, Mann AB, Livi KJ, Teaford MF, Weihs TP. Nanaoindentation mapping of the mechanical properties of human molar tooth enamel. Arch Oral Biol 2002; 47: 281-91.

[15] Ge J, Cui FZ, Wang XM, Feng HL. Property variations in the prism and the organic sheath within enamel by nano-indentation. Biomaterials 2005; 26: 3333-9.

[16] Habelitz S, Marshall SJ, Marshall GW, Balooch M. Mechanical properties of human dental enamel on the nanometer scale. Arch Oral Biol 2001; 46: 173-83.
[17] Bell E, Townsend G, Wilson D. Effect of Down syndrome on the dimensions of dental crowns and tissues. Am J Hum Biol 2001; 13 . 690-8.

[18] Zilberman U, Smith P, Kupietzky A, Mass E. The effect of hereditary disorders on tooth components: a radiographic morphometric study of two syndromes. Arch Oral Biol 2004; 49: 621-9.

[19] Townsend G. Tooth size in children and adults with Trisomy 21 "Down's Syndrome". Arch Oral Biol 1983; 28: 159-66.

[20] Townsend G. A correlative analysis of dental crown dimensions in individuals with Down syndrome. Hum Biol 1987; 59: 537-48.

[21] Cohen MM, Baum BJ, Garn SM. Crown-size reduction in congenital defects. In: Dahlberg AA, Graber TM, Eds. Orofacial growth and development. The Hague, Paris, Mouton Publishers 1977; 11926.

[22] McMillan RS, Kashgarian J. Relation of human abnormalities of structure and function to abnormalities of dentition. II. Mongolism. J Am Dent Assoc 1961; 63: 368-73.

[23] Brown T, Townsend GC. Size and shape of mandibular first molars in Down syndrome. Ann Hum Biol 1984; 11: 281-90.

[24] Peretz B, Shapira J, Farbstein H, Arieli E, Smith P. Modified cusp relationships of mandibular molar teeth in children with Down's syndrome. J Anat 1998; 193: 529-33.

[25] Scherzer AL. Early diagnosis, management, and treatment of cerebral palsy. Rehabil Lit 1974; 35: 194-9.

[26] Bhat NM, Nelson KB, Cummins SK, Grether JK. Relevance of developmental enamel defects in children with cerebral palsy. J Oral Pathol Med 1992; 21: 241-4.

[27] Dolk H, Pattenden S, Johnson A. Cerebral palsy, low birth weight and socio-economic deprivation: inequalities in a major cause of childhood disability. Paediatr Perinat Epidemiol 2001; 15: 359-63.

[28] Foster-Barber A, Dickens B, Ferriero DM. Human perinatal asphyxia: correlation of neonatal cytokines with MRI and outcome. Dev Neurosci 2001; 23: 213-18.

[29] Gray PH, Jones P, O'Callaghan MJ. Maternal antecedents for cerebral palsy in extremely preterm babies: a case-control study. Dev Med Child Neurol 2001; 43: 580-5.

[30] Noren JG, Gillberg C. Mineralization disturbances in the deciduous teeth of children with so called minimal brain dysfunction. Swed Dent J 1987; 11: 37-43.

[31] Caropreso S, Bondioli L, Capannolo D, Cerroni L, Macchiarelli R, Condo SG. Thin sections for hard tissue histology: a new procedure. J Microsc 2000; 199: 244-7.

[32] Robinson C, Shore RC, Brookes SJ, Strafford S, Wood SR, Kirkham J. The chemistry of enamel caries. Crit Rev Oral Biol 2000; 4: 481-95.

[33] Mahoney EK, Ismail FSM, Kilpatrick NM, Swain MV. Mechanical properties across Hypomineralized/hypolastic enamel of first permanent molar teeth. Eur J Oral Sci 2004; 112: 497-502.

[34] AL-Jawad M, Steuwer A, Kilcoyne SH, Shore RC, Cywinski R, Wood DJ. 2D mapping of texture and lattice parameters of dental enamel. Biomat 2007; 28: 2908-14.

[35] Du C, Falini G, Fermani S, Abbott C, Moradian-Oldak J. Supramolecular assembly of amelogenin nanospheres into birefringent microribbons. Science 2005; 307: 1450-4. 